\title{
Agronomy looking forward, thinking broadly
}

\author{
I. J. Titmarsh $^{\mathrm{A}, \mathrm{C}}$, J. Doughton ${ }^{\mathrm{A}}$, and E. Woods ${ }^{\mathrm{B}}$ \\ A Department of Employment, Economic Development and Innovation, PO Box 102, Toowoomba, \\ Qld 4350, Australia. \\ ${ }^{B}$ Department of Employment, Economic Development and Innovation, GPO Box 46, Brisbane, Qld 4001, Australia. \\ ${ }^{\mathrm{C} C}$ Corresponding author. Email: ian.titmarsh@bluemaxx.com.au
}

\begin{abstract}
Global trends in human population and agriculture dictate that future calls made on the resources (physical, human, financial) and systems involved in producing food will be increasingly more demanding and complex. Both plant breeding and improved agronomy lift the potential yield of crops, a key component in progressing farm yield, so society can reasonably expect both agronomy as a science and agronomists as practitioners to contribute to the successful delivery of necessary change. By reflecting on current trends in agricultural production (diversification, intensification, integration, industrialisation, automation) and deconstructing a futuristic scenario of attempting agricultural production on Mars, it seems the skills agronomists will require involve not only the mandatory elements of their discipline but also additional skills that enable engagement with, even leadership of, teams who integrate (in sum or part) engineering, (agri-)business, economics and operational management, and build the social capital required to create and maintain a diverse array of enhanced and new ethical production systems and achieve increasing efficiencies within them.
\end{abstract}

\section{Introduction}

Food security and quality of life are directly affected by the available natural resources, how they are used, and the number of people who must share them (Pimentel and Giampietro 1994). Based on projections of world population growth to between 9 and 11 billion by 2050 (United Nations 2007), it will be increasingly difficult to meet future basic human food needs given the finite resources of the Earth (Pimentel 2009).

Agriculture provides more than $99.7 \%$ of world food supply; the oceans and aquatic ecosystems less than $0.3 \%$ (Pimentel 2009). Increasing consumption of meat and biofuels by a growing population mean a burgeoning demand for grain (Fig. 1) but, while the quantity of grain produced per ha of land is still rising, productivity is not increasing fast enough to keep pace with demand (Fig. 2) (MacKenzie 2008; Fischer and Edmeades 2010).

Per capita yields in grain and some other staple crops are decreasing in consequence, and the emerging imbalance between the quantity of food crops produced and the number of people depending on these food resources is growing (Pimentel 2009).

Globally, prime agricultural land in agro-ecological zones favourable for production mostly has been identified or developed already; and is being lost at an alarming rate due to overuse and soil erosion by wind and water (Pimentel 1998). Lands currently underutilised, such as in the Ukraine, will provide some leeway in the short term but area expansion will at best be small, so future agricultural growth will be even more reliant on raising crop and animal yields (Fischer et al. 2009).

Despite land replacement strategies that impact forests and marginal land, world cropland per capita is around 0.25 ha and declining. Around 0.5 ha per capita is considered the minimum for the production of a diverse diet similar to that of the USA and Europe (Pimentel 1998). Some 0.83 ha were available to grow food for each American at the end of the 20th century, yet projections for population growth in the USA suggest only 0.25 ha will be available per capita by 2050 (Pimentel et al. 1998).

Net agricultural exporters such as Brazil, Argentina, the Netherlands and Australia will be increasingly important as sources of food since nations such as the USA and China already import as much as they export despite their enormous agricultural sectors (Australian Farm Institute 2009). On current trends in domestic food consumption and topsoil loss, it is likely the USA will cease to be a food exporter around 2025 as food grown in the USA then will be needed for domestic purposes (Pimentel and Giampietro 1994).

The development of agricultural systems that are more productive and sustainable is a key objective to redress the imbalance between food production and population (Pimentel 2009). That global demand for food has grown more rapidly than production over the past two decades is due partly at least to the reduced investment made in agricultural research and development (Fig. 3) (Pardey et al. 2006; Anon. 2008).

Linking the expected increase in global demand for agricultural product and the expected decrease in the availability of the resources on which production depends (arable land, water, etc.) allows us to project what agricultural systems need to deliver in the future. Stated simply, productivity must roughly double by 2050 (Tweeten and Thompson 2009). Working to that target the annual rate of growth in productivity across all of agriculture, meaning growth both in productivity 


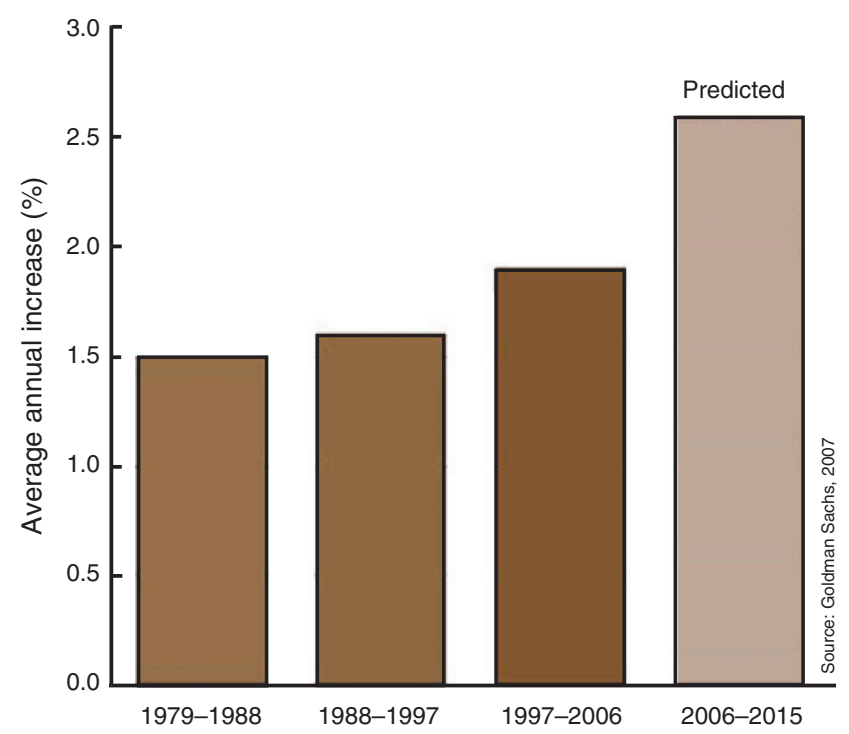

Fig. 1. Increase in the demand for grain, 1979-2015.

per unit area and total production, needs to double (to $1.8 \%$ p.a.) and be maintained from now until 2050. Simultaneously, environmental and agricultural practice must ensure the continuing productive capacity of natural resources, while mitigating and adapting to the effects of climate change.

Achieving this target will require a quantum leap in the production of commodities (Food and Agriculture Organisation of the United Nations 2006). Some argue that farmers have already maximised production from a given area of land but the evidence for this is thin (Anon. 2008) and is contrary to the innovative history of agricultural productivity. While advances in molecular biology expressed through genetic manipulation and superior genotypes will play a significant future

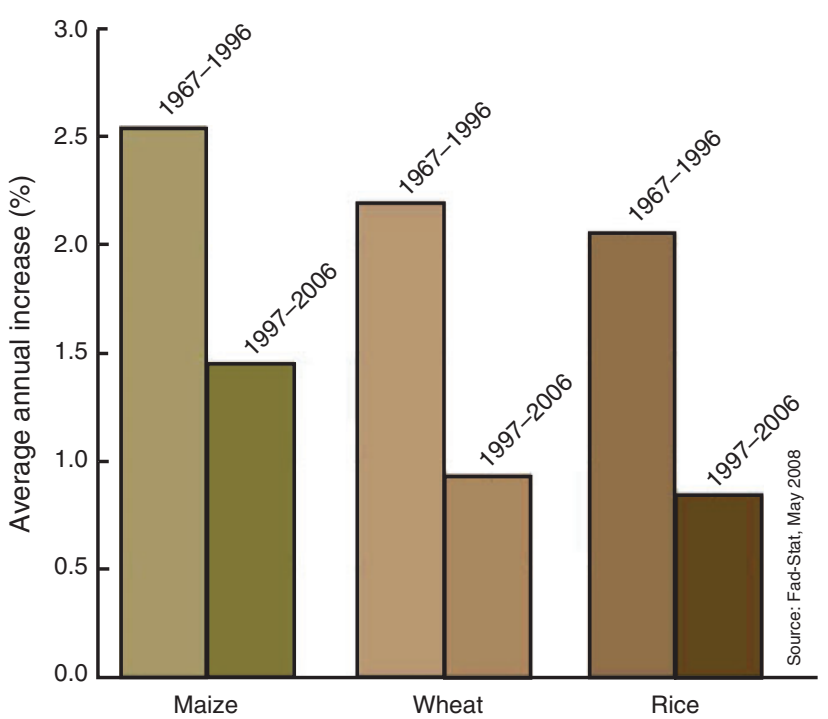

Fig. 2. Reduction in maize, wheat and rice yields; 1967-96 v. 1997-2006.

role in improving productivity, agricultural research in general and agronomy in particular are also about making the best use of knowledge and technologies that are already available (Anon. 2008).

The increasing need for diverse agronomic input and superlative enterprise management is clear.

\section{Trends}

Intensification and diversification

Agriculture has been expanding and intensifying for decades (MacLeod and Moller 2006; Maron and Fitzsimons 2007;

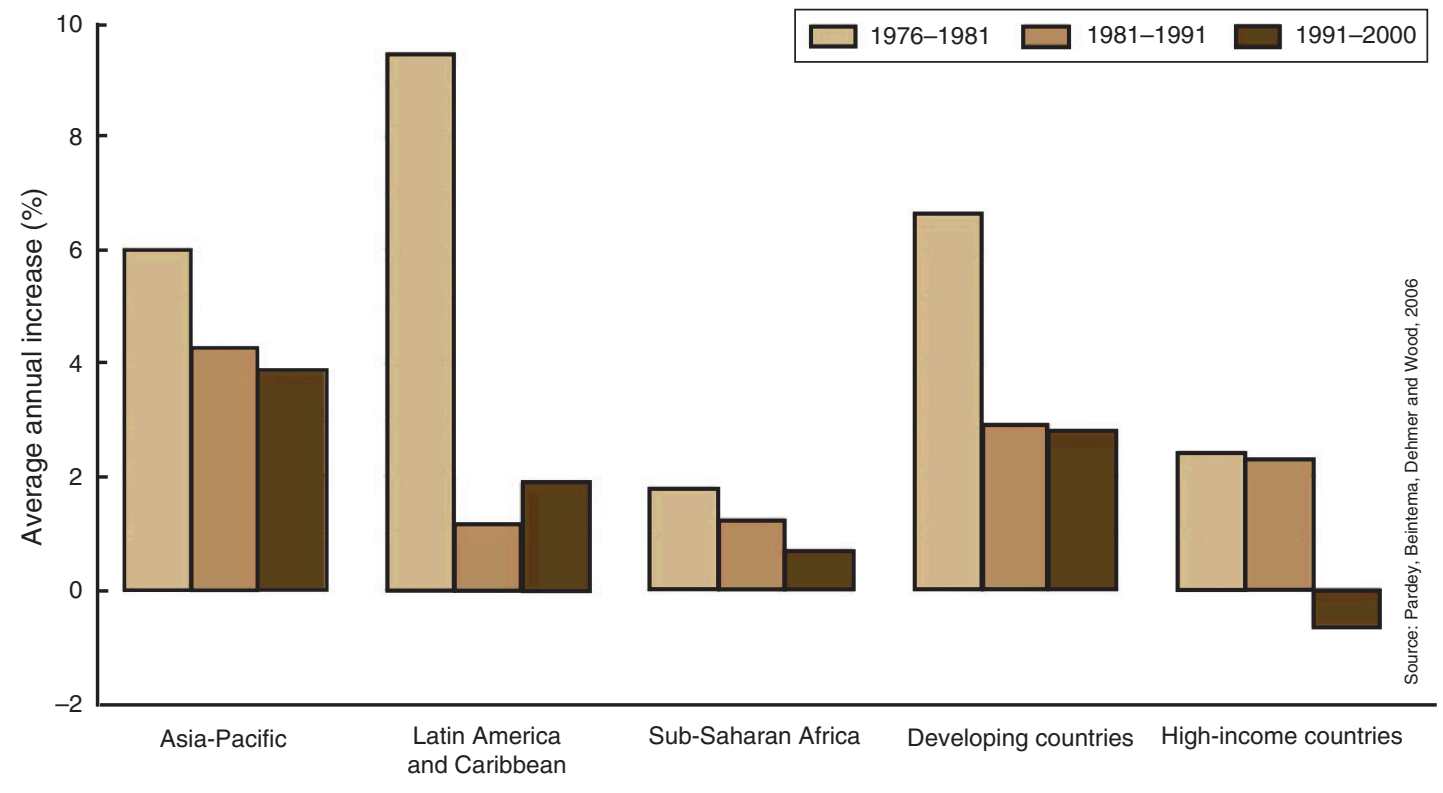

Agricultural R\&D spending

Fig. 3. Average annual increase in agricultural R\&D spending for 1976-81, 1981-91 and 1991-2000. 
Kang et al. 2008) because these are key elements in risk management and economic survival, even for Australian producers. Depending on the specific mix of agricultural activities and the ecological condition of farms, small changes to the production base can have large impacts on farm enterprise profitability (House et al. 2008).

With increasingly unpredictable natural and business environments, agricultural activities in each farm enterprise need to provide increased value while every producer needs to be more flexible in his or her activity mix to maximise profit in the coming years.

\section{Integration}

Major animal and plant production research programs in agriculture focus on alternative production approaches and the integration of production systems (Wagner 1999). This in turn energises a search for greater efficiencies in the face of resource limitations (e.g. in water use and/or reuse for co-production in grain and grazing, agroforestry and grazing, aquaculture and horticulture).

In many agricultural industries, easy gains have already been made by adopting technological advances affecting the components of systems (e.g. breeds, varieties, pesticides, mechanisation, management practices). Additional major gains will be achieved when further technological innovation and integration deliver more complex production systems that acknowledge and engage more of the variables that impact upon our desired outcomes. In concert with continuing innovation and integration, discrete smaller agronomic 'sub'-systems will be integrated into these larger, more encompassing systems.

Indicative larger systems already include:

(1) Using waste streams from plant or animal enterprises as inputs to production in alternative enterprises (e.g. effluent from farm dam or pond aquaculture into cotton and vegetable production),

(2) Using waste streams from plant and/or animal enterprises as inputs to green energy production (e.g. reject fruit and manure into biogas),

(3) Using waste streams from integrated plant and animal enterprises as inputs in production of the component enterprises (e.g. grains-feedlot-manure-amended organic composts-broadacre fertiliser), and

(4) Further integration within large family holdings and corporate farming operations, in a manner that is both horizontal (e.g. spatial spread of grazing properties, temporal spread of fruit maturity) and vertical (produce, process, market, export).

\section{Automation and autonomous systems}

Future challenges for technologies revolve around increasing production per unit of land and incorporating automated processes and other technological innovations that either reduce labour input or allow more precise agriculture (García et al. 2007). To this set of targets we add that automation must aid the integration of diverse activities by maximising efficiency in particular processes, in sets of complementary processes, and in any combined use and reuse of resources.
The potential for automation to achieve such efficiencies is favoured by the continuing trend for exponential growth in computing capability, which is expected to continue for at least another decade. Satellites, visual systems and augmented reality, microsensor networks (Bulusu et al. 2004) and nanotechnology offer us the potential to 'measure to manage' relevant activities across more than 10 orders of magnitude. Increasingly, it will be possible to intervene from anywhere; through connectivity of any terminal on any system and the seamless integration of wire, fibre, cellular and wireless services.

Pervasive microsensor networks in particular promise to revolutionise the way we understand and construct complex physical systems as such devices, deeply embedded, will measure aspects of their environment in unprecedented detail. The many potential applications for such networks include: physiological monitoring, environmental monitoring (air, water, soil, chemistry), smart spaces, surveillance, precision agriculture, factory instrumentation, transportation, and inventory tracking (Bulusu et al. 2004).

Proponents of automation seek autonomous systems with the ability to self-monitor and self-correct. Such systems represent the next great step in the fusion of machines, computing, sensing, and software to create intelligent systems capable of interacting with the complexities of the real world. They are the physical and philosophical embodiment of machine intelligence, making appropriate decisions without reference to any human assistance. In this context microsensors and other components must self-configure, that is autonomously measure and adapt their properties to current conditions rather than rely on preconfiguration or manual reconfiguration in order to achieve robust, unattended operation in any environment (Bulusu et al. 2004).

Likewise, the focus of field robotics is to develop automation that expands product capabilities through the integration of systems technologies; including localisation, control systems, sensing, drive-by-wire, artificial intelligence, tele-operation, and semi- or fully-autonomous capability. Already an existing prototype of autonomous John Deere tractor has demonstrated how removing the constraints of onboard human operators can lead to revolutionary redesign of current systems.

Autonomy will eventuate in systems across a range of applications including resource monitoring and amelioration; managing production processes and product quality; maintaining food safety; even marketing (including spotmarket for quantity and quality mixes to specification).

\section{Industrialisation}

The $80 / 20$ rule, whereby the largest $20 \%$ of enterprises produce $80 \%$ of the product, has been bolstered in many of our agricultural industries by the loss of middle-sized producers creating a bimodal distribution in the number of enterprises of particular sizes. Large agribusinesses often are associated with pan-national and international operations and the rapid growth experienced by the largest $20 \%$ of Australian producers is mirrored by significant agribusinesses in China, India, and Brazil. Shareholder value is held in firm focus by these operators.

For larger producers, trends invite industrialisation of processes. Biotic potential and erratic abiotic elements are 
more controllable under contained production conditions such as in glasshouses; and enclosure invites the automation of controls. Increased capacity for control improves producers' perception of their ability to consistently meet the needs of customers and investors.

Industrialisation brings its own intensification agenda, promising 'designer' organisms with functional foci and even further technological intervention like gene silencing as opposed to the traditional varietal resistance gained from targeted breeding programs.

Industrialised production potentially can be uncoupled from traditional settings (e.g. land-based tank aquaculture of oceanic fish species), and focus on producing just the useful parts of plants and animals (continuous production) rather than growing whole plants and animals (batch production). Already a European patent exists for producing cotton lint without a cotton plant, and the first 'In Vitro Meat Symposium' was held in Norway in 2008 where scientists agreed 'victimless' beef, pork and chicken will be reality within a decade.

\section{Impacts}

Expansion of intensified and diversified agriculture is placing mounting pressures on resources and the broader environment (MacLeod and Moller 2006; Maron and Fitzsimons 2007; Kang et al. 2008). Current political machinations over water flows in the Murray-Darling basin are indicative of the types of challenges we must now face if we are to avoid the disasters being experienced elsewhere (Kang et al. 2008).

Credible paths forward are not yet clear. Resource limitations and increasing climatic uncertainty invite technological solutions but the practicalities of implementing such solutions on-farm have themselves raised new and diverse issues that, unless understood, will jeopardise effective adaptation and implementation by producers (García et al. 2007). Similarly, while integration and industrialisation offer hope that less land used for agriculture means more land available for the environment and biodiversity, there is considerable debate over the merits of 'wildlife-friendly farming', which incorporates conservation across the whole farming landscape versus sparing land deliberately for conservation and sacrificing other land for agriculture (House et al. 2008).

A trend towards 'getting big or getting out' is not complete. Principals of many smaller holdings have gone off-farm to diversify income or meet shortfalls. As future productivity growth in such smaller enterprises is likely to be less relative to highly commercial ones, the potential for doubling their productivity is moot.

The question of whether animals are sentient has enormous implications for how humans treat other species, including farm animals raised in factory farms for human consumption. Systems and goals to achieve the greatest output from the least input are now commonly seen as subjecting farm animals to constant physical and psychological stress. Increasing numbers of consumers concerned about animal welfare are questioning whether established production systems are 'ethical' if costefficiency and profit margin have taken priority.

Furthermore, many consumers reject the idea of 'multinational' and industrial food, and long-standing cultural preferences are being joined by an emerging demand for 'locally grown' produce. In exercising choice, consumers are looking for options and purchasing decisions are increasingly influenced by their perceptions of agricultural production processes. Consequently, there is increasing demand for products that are 'clean and green' and produced to high ethical standards. This is particularly evident in discerning markets, where the potential profits are highest.

Consumer preparedness to pay for the higher cost products of specialist systems pressures producers to increase the productivity of these systems to maximise the return on their investment. Ethical production systems with 'clean and green' credentials require measurement of system parameters and traceability of products to demonstrate that unacceptable processes and practices have been avoided.

Higher level human concerns and aspirations also will influence public policy on 'where our food comes from', particularly in relation to food sovereignty and food security, and also health imperatives - how food can prevent or minimise disease by being made more 'nutritious'.

\section{Premise}

Defining agronomy as 'the science and technology of utilising plants for food, fuel, feed and fibre' implies agronomists must play pivotal roles; firstly in providing the increased agricultural output our future demands, and secondly in developing efficient agricultural systems and practices that promote producers' participation while protecting and preserving the soil, water, and ecosystems that underwrite elevated levels of production.

The future challenge as to how agronomists engage professionally in production systems that are intensified, diversified, integrated, automated perhaps autonomous, and industrialised - and with the impacts of such systems - may be more about agronomists themselves than agronomy per se.

\section{Envisaged skill sets}

Without prescribing answers, how will agronomists be a vehicle through which these agricultural trends and possibilities materialise?

An 'elastic-sided boot agronomist with 3G laptop connection' is already utilising significant technology at the coalface - in the field, in real time. Such agronomists are foot soldiers in the march of overlapping trends of intensification, diversification and integration and are taking meaningful action now towards 'keeping it all real'.

A 'nerd agronomist' is engaging now with the present and potential technologies that enable efficiency and automation and, eventually, autonomous management of our agricultural production systems.

Significant new investment will be required to influence and increase the momentum for change. New manifestations of agricultural intensification, diversification and industrialisation, including their integration and automation, all require prior conceptualisation of the possibilities and their likely benefits. So a 'stock market agronomist' will be required to participate in, perhaps even lead the multi-disciplinary teams required to write 
the business cases, raise needed capital, and later manage shareholder value in these new ventures.

Clearly, undergraduate education is capable of delivering agronomists with significant traditional skills; yet were a broader range of discipline areas such as finance and economics required to be covered then capable but less-specialised professionals may be a direct consequence. Proposing and implementing agricultural innovation, managing longer-term income streams and growing wealth assets, especially as employees of publicly listed companies, mean the 'stock market agronomists' will likely be working with team members that include accountants, biotechnologists, commodity traders, economists, livestock specialists and patent lawyers, among others. Such teams are already being used by some consultant groups to advise larger farm enterprises and teams may even be the preferred option. The non-traditional skills required here may only be developed through relevant post-graduate study, effective cross-discipline mentoring and significant professional experience.

If that all sounds too much then a 'big picture, sensitive, new age agronomist' works in the context of production systems to meet the new and strongly felt political and ethical realities. Our future challenge on food supply will drive increasing interest in the interactions between food and human health, particularly in relation to the developing world.

\section{Contemplating a distant future}

Agronomy has its origins as a system discipline, and now that scope is expanding; perhaps exponentially. Systems agronomy is a path forward but both increased RD\&E capability and capacity are required to design, develop and implement enhanced and new production systems that deliver sustainability, ecosystem services, sociological outcomes, and more.

Elements of these new systems are evident already. Growing greenhouse vegetables is an exacting and intense form of agricultural enterprise and the technology of greenhouse food production already utilises automatic or autonomous systems and is changing rapidly. Such systems today produce yields never before realised and the future for these hydroponic or soil-less cultured systems appears more positive today than at any previous time.

Progressing enclosure of production from a glasshouse to a glasshouse with hydroponics, to a biosphere, to conducting agriculture in space is a process analogous to intensification and industrialisation involving heightened, even ultra, levels of control. A variety of crops grow well in space and deliver large volumes of produce (tomatoes, corn, wheat, potatoes, salad greens) yet the real importance of whatever lessons come out of biosphere experiments, while they may aid a space effort, is going to be on Earth; in demonstrating how bio-regenerative life-support systems can help us to produce intensively and do no harm.

Conducting a thought experiment around how to produce food on Mars, and later deconstructing that scenario, provides insight as to the nature of the challenge and gives us a perspective on how to take meaningful action now.

Images of the Martian landscape now are numerous and readily accessible. Contemplating any image of this landscape conjures up myriad questions - is this arable land? Do we choose soil-based production? How do we contain it? What is a sufficient level of containment? Who builds the containment structure? What are the necessary primary resources and inputs (e.g. atmosphere) and where do they come from? What will be produced and who will produce it? Can we get sustainable energy production as a by-product? How will our produce meet consumer expectations for 'clean, green, ethical' production and food safety? Will 'food miles' and traceability be issues? Does Martian-sourced produce have sustainable natural resource credentials? How do we 'do' sustainability on Mars? What is ecological harmony on Mars or is Martian agriculture simply environmental vandalism? How do we make it happen? How do we pay for it? What happens if we make a mistake? Which professionals in which disciplines should be talking now as we commence moving towards this new reality?

The answers to these questions will be different for each of us but suggest the sorts of skills that need to be incorporated in the team required to manifest the vision.

\section{Looking forward, broadly}

As agronomists we can look forward to a new and exciting future, but it will be much different to what we expect. Some assume we can divine the future by extrapolating the present yet, if we use the past as a guide, then our future will be nothing like we imagine. Extrapolated predictions often occur much more slowly and painfully than expected while real and rapid change comes from totally new areas (e.g. the Internet).

Agronomists' roles in the world to come undoubtedly will be more diverse and complex. They will be no less specialised in the basic and traditional skills but, putting this together with an ability to synthesise ideas, systems and 'outside-the-box' solutions from an ever-widening range of science and technology means their roles reflect the 'systems'-focused nature of their work. Because no-one alone is likely to have all the relevant skills, the role also will be about being a successful integrator of the people who possess the knowledge and skills required to successfully develop complex and integrated production systems which deliver productivity growth within a political and economic context. What role an agronomist plays overall in the dynamics of production from systems that integrate multiple enterprises probably will more likely reflect the innate qualities of the individual rather than their agronomic roots.

Much of our technological success has been based on the availability of land, water, energy, and biological resources of the Earth. Yet no known or future technology will be able to double the world's arable land, and no available technologies can double the flow of our rivers (Pimentel 1998). While relevant sciences, including agronomy, have been neglected in recent years, current approaches to maximising production within agricultural systems are unsustainable and new methodologies utilising all elements of such systems are needed (The Royal Society 2009).

Change is inevitable whether or not we embrace it. One possibility is we engage joyfully in creating desirable and informed change and accelerating observable positive change as it happens around us. More radically, it may be time to expand our horizons and explore an alien world (such as Mars) with as much land surface as Earth; which could reshape the way we think about our place in the Universe and inspire a new generation to 
embark on careers in science, technology, and engineering (Aldrin 2007). Some experts believe Mars can be transformed into an environment that resembles Earth - through a process known as 'terraforming'; in the absence of which true long-term colonisation is unlikely (Lovett 2007).

What, and how, could agronomy and agronomists contribute to that?

\section{References}

Aldrin B (2007) Mars: the next giant leap. Cosmos 18, 53.

Anon. (2008) Editorial: how science can help feed the world. New Scientist 2660, 3 .

Australian Farm Institute (2009) Following on: Australian agriculture's role in global food security. Farm Institute Insights 6(3), 7.

Bulusu N, Heidemann J, Estrin D, Tran T (2004) Self-configuring localization systems: design and experimental evaluation. $A C M$ Transactions on Embedded Computing Systems 3, 24-60. doi:10.1145/ 972627.972630

Fischer RA, Byerlee D, Edmeades GO (2009) Can technology deliver on the yield challenge to 2050? In 'Expert Meeting on How to Feed the World in 2050'. Rome, 24-26 June 2009. (Economic and Social Development Department, Food and Agriculture Organization of the United Nations: Rome)

Fischer RA, Edmeades GO (2010) Breeding and cereal yield progress. Crop Science 50, S-85-S-98. doi:10.2135/cropsci2009.10.0564

Food and Agriculture Organisation of the United Nations (2006) World agriculture: towards 2030/2050. Interim Report. Prospects for food, nutrition, agriculture and major commodity groups. Available at: www.fao.org/ES/esd/AT2050web.pdf (accessed 4 March 2009)

García SC, Fulkerson WJ, Nettle R, Kenny S, Armstrong D (2007) FutureDairy: a national, multidisciplinary project to assist dairy farmers to manage future challenges - methods and early findings. Australian Journal of Experimental Agriculture 47, 1025-1031. doi:10.1071/EA06064

House APN, MacLeod ND, Cullen B, Whitbread AM, Brown SD, McIvor JG (2008) Integrating production and natural resource management on mixed farms in eastern Australia: the cost of conservation in agricultural landscapes. Agriculture, Ecosystems \& Environment 127, 153-165. doi:10.1016/j.agee.2008.03.011

Kang S, Su X, Tong L, Zhang J, Zhang L, Davies WJ (2008) A warning from an ancient oasis: intensive human activities are leading to potential ecological and social catastrophe. The International Journal of Sustainable Development and World Ecology 15, 440-447. doi:10.3843/SusDev.15.5:5
Lovett RA (2007) Next stop: Mars. Cosmos 18, 54-61.

MacKenzie D (2008) What price more food? New Scientist 198(2660), 28-33. doi:10.1016/S0262-4079(08)61491-8

MacLeod CJ, Moller H (2006) Intensification and diversification of New Zealand agriculture since 1960: an evaluation of current indicators of land use change. Agriculture, Ecosystems \& Environment 115, 201-218. doi:10.1016/j.agee.2006.01.003

Maron M, Fitzsimons JA (2007) Agricultural intensification and loss of matrix habitat over 23 years in the West Wimmera, south-eastern Australia. Biological Conservation 135, 587-593. doi:10.1016/j.biocon. 2006.10.051

Pardey PG, Beintema NM, Dehmer S, Wood S (2006) Agricultural research: a growing global divide? IFPRI Food Policy Report, Washington, DC.

Pimentel D (1998) Population growth and the environment: planetary stewardship. Electronic Green Journal 1(9), Available at: http:// escholarship.org/uc/item/8g67g6ng (accessed 8 June 2010)

Pimentel D (2009) Agriculture and food problems. In 'Principles of environmental sciences'. (Eds JJ Boersema, L Reijnders) pp. 513-517. (Springer Science + Business Media B.V.)

Pimentel D, Giampietro M (1994) Global population, food and the environment. Trends in Ecology \& Evolution 9, 239. doi:10.1016/ 0169-5347(94)90262-3

Pimentel D, Giampietro M, Bukkens SGF (1998) An optimum population for North and Latin America. Population and Environment 20, 125-148. doi:10.1023/A:1023367211000

The Royal Society (2009) Reaping the benefits: science and the sustainable intensification of global agriculture. RS Policy Document 11/09. Issued: October 2009 RS1608. Available at: http://royalsociety.org/Report_WF. aspx?pageid $=11210 \&$ terms $=$ reaping + the + benefits $\&$ fragment $=\&$ Search Type $=\&$ terms $=$ reaping $\% 20$ the $\% 20$ benefits

Tweeten L, Thompson SR (2009) Long-term global agricultural output supply-demand balance. Farm Policy Journal 6(1), 1-16.

United Nations (2007) World population will increase by 2.5 billion by 2050. Available at: www.un.org/News/Press/docs//2007/pop952.doc.htm (accessed 4 March 2009)

Wagner WC (1999) Sustainable agriculture: how to sustain a production system in a changing environment. International Journal for Parasitology 29, 1-5. doi:10.1016/S0020-7519(98)00173-8

Manuscript received 4 January 2010, accepted 21 April 2010 